\title{
Vasculite cutânea crioglobulinêmica induzida por infecção crônica pelo vírus da hepatite $\mathrm{C}^{*}$ Cutaneuos cryoglobulinemic vasculitis induced by chronic bepatitis $C$ virus infection *
}

\author{
Maurício Pedreira Paixão ${ }^{1}$
}

Hélio Amante $\operatorname{Miot}^{2}$

\begin{abstract}
Resumo: As vasculites cutâneas podem representar grande desafio clínico, mesmo após exame dermatológico cuidadoso e realização de exames complementares. Os autores apresentam caso de vasculite crioglobulinêmica cutânea associada à infecção crônica pelo vírus da hepatite $\mathrm{C}$, salientando a importância do exame dermatológico na investigação diagnóstica. Discutem ainda a importância da busca da etiologia e da correta classificação no prognóstico e terapêutica das vasculites cutâneas.

Palavras-chave: Crioglobulinemia, Hepatite C, Vasculite
\end{abstract}

\begin{abstract}
Cutaneous vasculitis may represent a great clinical challenge, even after careful dermatological examination and laboratory assessment. The authors present a case of cutaneous cryoglobulinemic vasculitis associated to chronic hepatitis $C$ virus infection, pointing out the importance of the dermatological examination for diagnostic investigation. They discuss about the importance of defining the etiology and making correct classification for appropriate prognosis and treatment of cutaneous vasculitis.
\end{abstract}

Keywords: Cryoglobulinemia, Hepatitis C, Vasculitis

\section{INTRODUÇÃO}

As vasculites representam grupo de afecções que se caracterizam fundamentalmente por infiltrado inflamatório envolvendo a parede dos vasos sangüíneos. Podem acometer vasos de diferentes calibres, afetando o sistema arterial, venoso ou ambos. Por conseguinte, diversos órgãos e sistemas podem estar implicados. A pele, nesse contexto, é órgão comumente acometido pelas vasculites, e o dermatologista é, freqüentemente, o primeiro especialista a ser procurado por esses pacientes. Quanto à etiologia, podem ser primárias ou secundárias a doenças sistêmicas. ${ }^{1}$

Devido à miríade de manifestações sistêmicas e da grande variedade de etiologias relacionadas às vas- culites, foram propostas diferentes classificações e nomenclaturas para esses quadros. Classificações mais atuais de vasculites bastante usadas são as do American College of Rheumatology de $1990^{2}$ e o consenso de Chapel Hill, de 1994.,

O presente caso ilustra como o exercício do exame clínico, associado à adequada propedêutica laboratorial, permitiu diagnóstico correto e estabelecimento de plano terapêutico individualizado.

\section{RELATO DO CASO}

C.T.O.L., do sexo feminino, 33 anos, do lar, referiu o aparecimento há 10 meses de lesões nos terços distais dos membros inferiores, incluindo cianose,

\footnotetext{
Recebido em 22.02.2006.

Aprovado pelo Conselho Consultivo e aceito para publicação em 25.03.2007.

* Trabalho realizado no atendimento ambulatorial em clínica privada em Santo André (SP), Brasil.

Conflito de interesse: Nenhum / Conflict of interest: None

Suporte financeiro: Nenhum / Financial funding: None

Doutorando da Disciplina de Telemedicina da Faculdade de Medicina da Universidade de São Paulo (FMUSP) - São Paulo (SP). Especialização em Cirurgia Dermatológica pela Faculdade de Medicina do ABC - Santo André (SP), Brasil.

Professor doutor do Departamento de Dermatologia e Radioterapia da Faculdade de Medicina de Botucatu (FMB), Universidade Estadual Paulista (Unesp) Botucatu (SP), Brasil.

(C)2008 by Anais Brasileiros de Dermatologia
} 
livedo reticular, pápulas e placas purpúricas de dimensões variadas, com diâmetro inferior a $1,5 \mathrm{~cm}$, bem delimitadas (Figuras 1 e 2), por vezes com coloração mais violácea e exibindo pequenas crostas na superfície. Concomitantemente, referia artralgia e adinamia. Informou outros episódios semelhantes prévios, com agravamento nos meses mais frios, tendo feito uso de sintomáticos por indicação médica em postos de saúde, sem melhora. Negava transfusão sangüínea e outras queixas sistêmicas. Não foram observadas mais alterações ao exame clínico. Durante a primeira consulta foi orientada a suspensão de medicações e realização de exames complementares. Pela presença de púrpuras palpáveis no momento da consulta, optou-se pela realização de biópsia cutânea em uma dessas lesões.

Os primeiros exames solicitados foram: VHS, proteína $\mathrm{C}$ reativa, hemograma, Aslo, c-Anca e p-Anca, VDRL, FAN, fator reumatóide, urina I, parasitológico de fezes, sorologia para HIV, hepatites B e C, transaminases hepáticas, dosagem de crioglobulinas, complemento e exame anatomopatológico da biópsia cutânea.

Foi orientado uso de prednisona $(40 \mathrm{mg} / \mathrm{d})$ até o resultado dos exames, observando-se melhora do quadro clínico.

Em meio aos exames alterados, observou-se a presença de crioglobulinas e sorologia positiva para hepatite C. O exame histopatológico da lesão cutânea revelou vasculite leucocitoclástica envolvendo pequenos vasos (Figura 3).

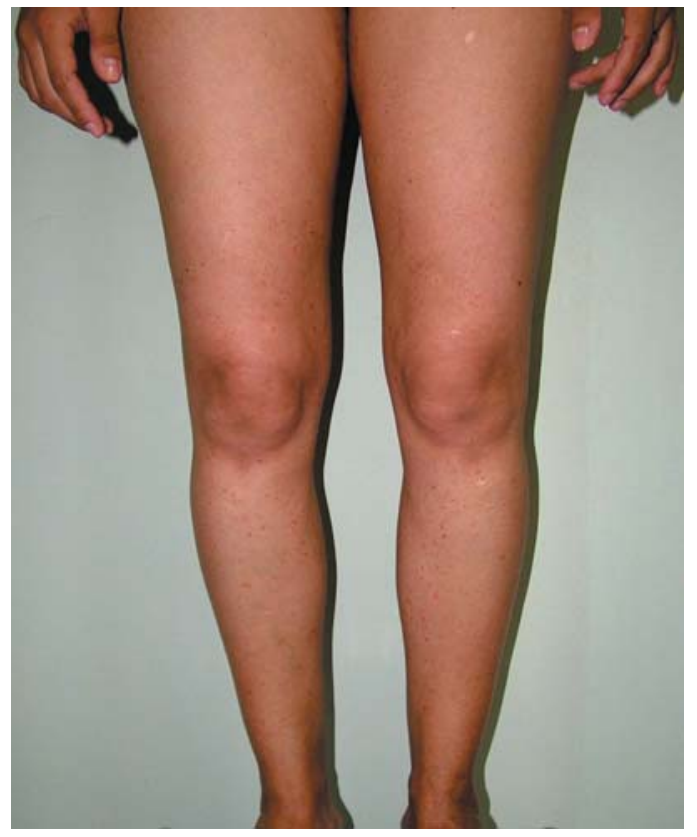

Figura 1: Pápulas purpúricas na face anterior das coxas e das pernas
Após resultado dos exames laboratoriais foi suspensa a prednisona, e a paciente foi encaminhada para o Serviço de Infectologia, onde foi realizada biópsia hepática, dosagem de carga viral e genotipagem para vírus $\mathrm{C}$. A biópsia hepática revelou a presença de infiltrado inflamatório em porções septais e portais, ausência de necrose em saca-bocado e de pigmentos, sendo compatível com hepatite crônica por vírus $\mathrm{C}$ discretamente ativa (Figura 4). $\mathrm{O}$ genótipo do vírus $C$ identificado foi $\mathrm{o} 1 \mathrm{~b}$. A análise quantitativa da carga viral revelou mais de três milhões de cópias (log da carga viral superior a seis).

Foram orientados cuidados gerais quanto à exposição ao frio e retornos periódicos à clínica dermatológica, observando-se involução das lesões cutâneas, com raros episódios de menor intensidade durante o inverno. Após planejamento conjunto com o Serviço de Infectologia do Hospital Emílio Ribas, indicou-se o uso de interferon-alfa (IFN- $\alpha$ ) peguilado e ribavirina para o tratamento da hepatite $\mathrm{C}$.

\section{DISCUSSÃO}

As vasculites representam grupo bastante heterogêneo de afecções, e sua gravidade varia desde doença autolimitada com acometimento cutâneo discreto até quadros extremamente graves cursando com falência de múltiplos órgãos. Representam área de interface em que podem atuar o dermatologista, o reumatologista e o infectologista, além de outras especialidades.

A investigação das vasculites cutâneas envolve história e exames clínicos minuciosos, caracterização histopatológica e busca racional a partir de exames complementares. A elaboração de estratégia sistematizada pode facilitar a elucidação diagnóstica, e nesse sentido foi elaborado o fluxograma a seguir (Figura 5).

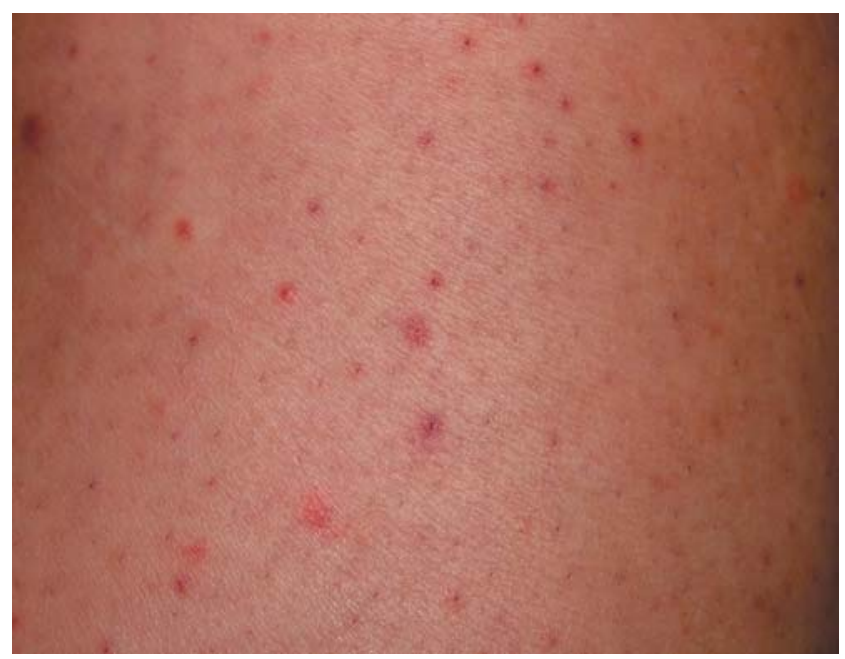

Figura 2: Pápulas purpúricas na face anterior das coxas e das pernas 


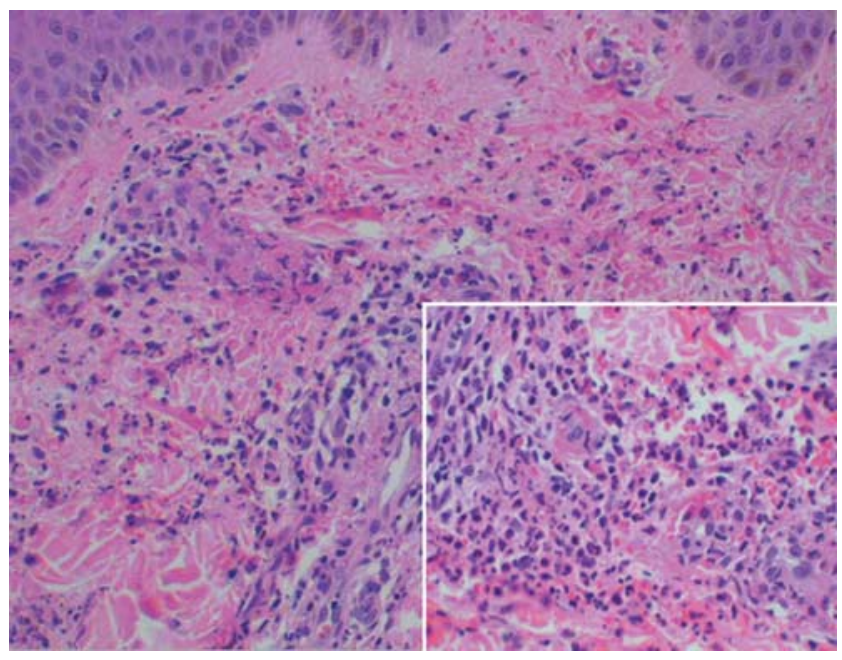

Figura 3: Exame histopatológico de fragmento de pele demonstrando vasculite leucocitoclásica dos pequenos vasos superficiais da derme (H\&E 10x). Detalhe no canto inferior demonstrando cariorrexe e extravasamento de hemácias (H\&E 40x)

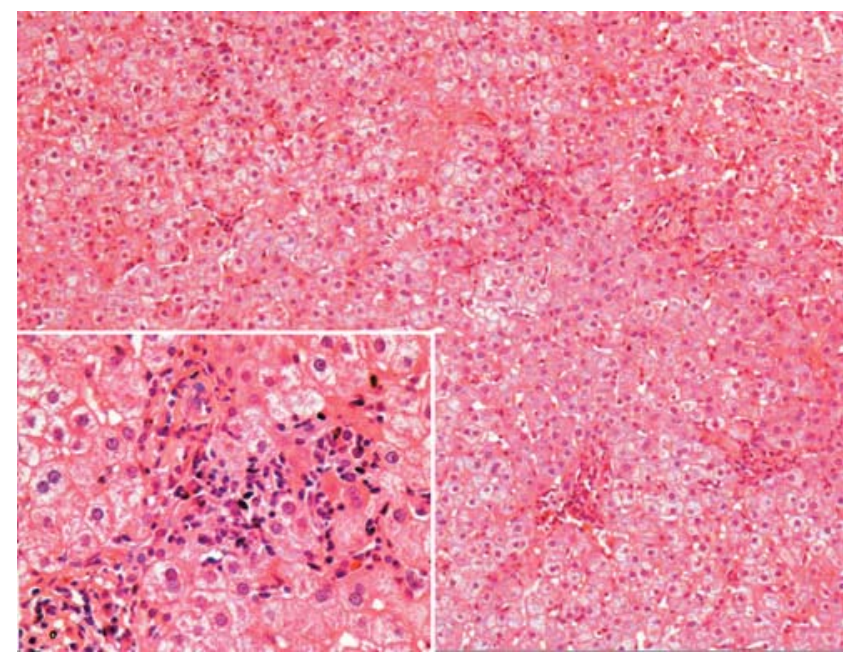

FigurA 4: Biópsia hepática com discreto infiltrado inflamatório em porções septais e portais evidenciando hepatite crônica com discreta atividade (H\&E 10x). Detalhe no canto inferior esquerdo do infiltrado inflamatório predominantemente linfocitário (H\&E 40x)
Como visto até aqui, a abordagem das vasculites pode representar um grande desafio diagnóstico ao clínico, e as dificuldades em sua abordagem partem das tentativas de classificação. A classificação do American College of Rheumatology, de 1990, inclui critérios clínicos e histológicos, e a classificação de 1994, obtida por consenso internacional em Chapel Hill, divide as vasculites de acordo com os calibres dos vasos. Portanto, diferentes aspectos são tipificados e singularizados, existindo certo grau de sobreposição e dificultando a completa transposição entre elas., ${ }^{5,6}$

Na década de 1950, Pearl Zeek descreveu quadros de vasculite de pequenos vasos com acometimento cutâneo resultado de exposição a droga, denominando-os vasculite de hipersensibilidade. Mais recentemente, dentre as vasculites com acometimento cutâneo, salienta-se um subgrupo chamado de vasculite cutânea de pequenos vasos (VCPV), definido após o consenso de Chapel Hill. ${ }^{5.8}$ Há, porém, autores que insistem em caracterizar a VCPV como entidade clínica própria, com acometimento cutâneo exclusivo e comumente associada ao uso de medicações ou a infecções. ${ }^{5}$ Esse subgrupo apresenta um espectro de lesões cutâneas, sendo a púrpura palpável a mais comum. Seus achados histopatológicos característicos incluem inflamação angiocêntrica e segmentar, edema endotelial, necrose fibrinóide da parede do vaso e infiltrado celular composto predominantemente de neutrófilos com fragmentação nuclear (cariorrexe). Os vasos acometidos são as vênulas pós-capilares, apresentando padrão histopatológico de vasculite leucocitoclástica com potencial participação de imunocomplexos em sua patogênese. ${ }^{5,7}$ As VCPV podem ser encontradas em crianças e em adultos, sendo mais comum o aparecimento entre 34 e 49 anos, com a pro- porção mulher/homem variando de 2:1 a 3:1. Quadros clínicos recidivantes sugerem a associação de crioglobulinemia e infecção por vírus da hepatite $C^{8,9}$

A identificação da presença de crioglobulinas, como no presente caso, associada à positividade sorológica para o vírus $\mathrm{C}$, aponta para o diagnóstico definitivo. Investigações subseqüentes, como genotipagem, carga viral e biópsia hepática, foram de grande valia nos julgamentos voltados para o prognóstico e o tratamento.

A crioglobulina é um crioprecipitado de imunoglobulinas (Ig) que pode ser do tipo monoclonal ou policlonal. Segundo a classificação de Brouet, ${ }^{10}$ no tipo I encontra-se Ig monoclonal do tipo M (IgM) ou $\mathrm{G}$ (IgG), que normalmente não forma complexos, mas pode causar sintomas quando oclui vasos. É vista nas doenças hematológicas malignas. Nos tipos II e III, encontra-se a presença de anticorpos IgM monoclonal (tipo II) e policlonal (tipo III) dirigidos contra IgG policlonais; estes últimos constituem a crioglobulinemia mista essencial. ${ }^{10,11}$ Desde a descoberta do vírus $\mathrm{C}$, em 1989, aproximadamente $75-90 \%$ dos casos até então reconhecidos como essenciais passaram a ter um agente causal identificado, o que pode questionar a palavra "essencial" na nomenclatura., ${ }^{5,12}$

O achado clínico característico nas vasculites crioglobulinêmicas (VC) é a presença de púrpura palpável, normalmente restrita às extremidades inferiores. É relatada piora com o frio, presença de acrocianose, livedo reticular, artralgias e adinamia. Podem ser encontrados fator reumatóide, fator antinúcleo e outros auto-anticorpos (antimúsculo liso, anti-Ro/La e c-Anca), e hipocomplementemia, além de alterações renais e neurológicas. ${ }^{12}$

Quanto ao tratamento, a paciente possuía 


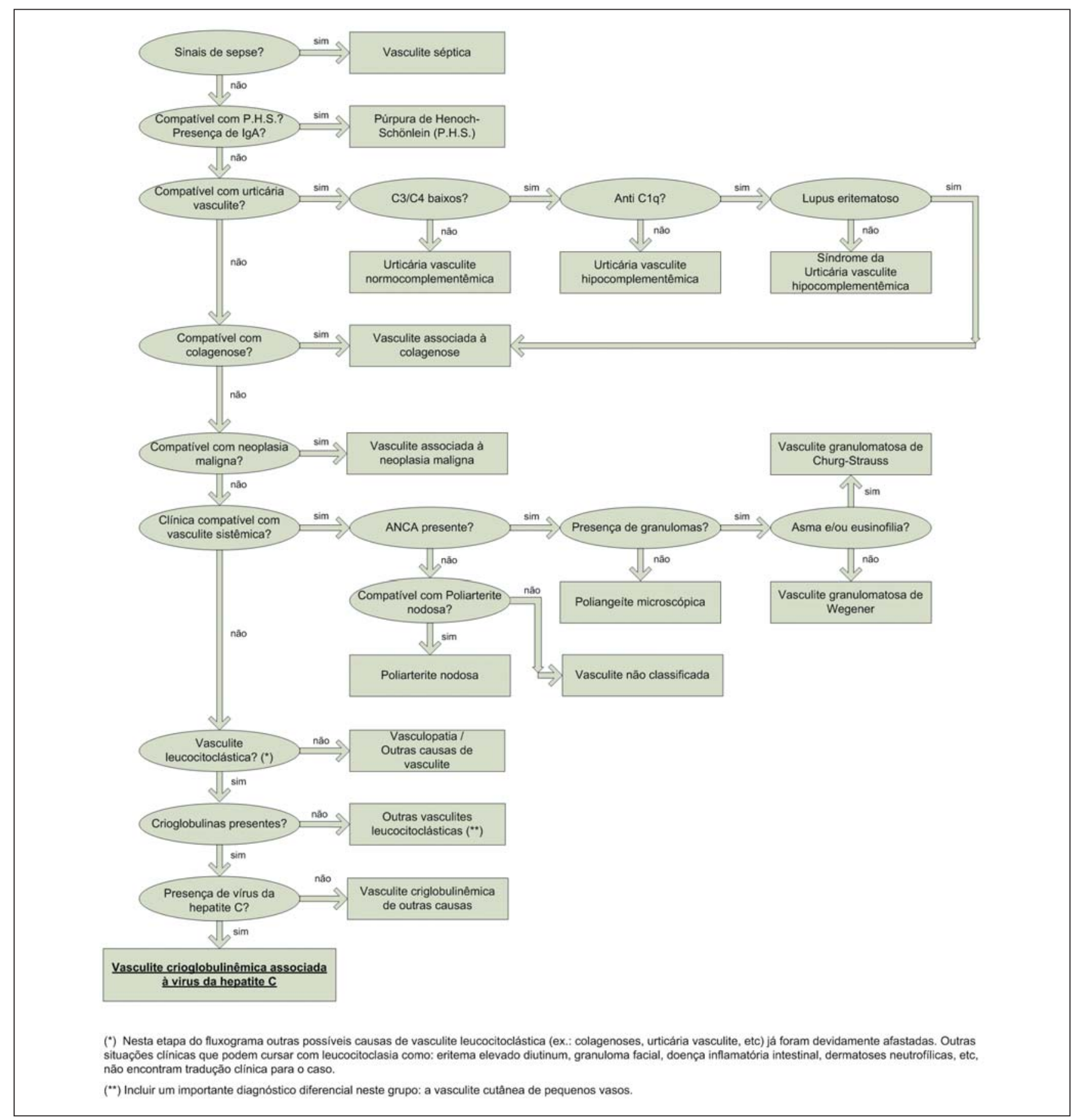

Fonte adaptada: Fiorentino $\mathrm{DF}^{5}$

FIGURA 5: Fluxograma para avaliação das vasculites cutâneas

carga viral elevada e o genótipo $1 \mathrm{~b}$, encontrado principalmente no Japão e em países ocidentais, ambos associados à resistência terapêutica, mesmo com a terapia combinada de IFN- $\alpha$ associado à ribavirina. ${ }^{13}$

Já foram descritas melhoras do quadro imunológico hepático e das lesões cutâneas em pacientes que utilizaram IFN- $\alpha$, quer por seu efeito direto imunomo- dulador, quer por seu efeito indireto sobre o vírus. $\mathrm{O}$ tratamento sugerido conta com a utilização de IFN- $\alpha$, do tipo $2 \mathrm{a}$ ou $2 \mathrm{~b}$ peguilado, pois apresenta maior meia-vida e menor antigenicidade em comparação ao convencional recombinante. A associação do IFN- $\alpha$ com ribavirina é descrita como apresentando efeito mais favorável para esse genótipo do que o IFN- $\alpha$ isoladamente. ${ }^{5,14,15}$ 
Outras condutas terapêuticas utilizadas incluem desde a simples monitoração do paciente para quadros assintomáticos até esquemas mais complexos incluindo plasma, corticosteróides, ciclofosfamida e rituximab, reservados para casos mais graves que cursam com glomerulonefrite rapidamente progressiva, neuropatia sensoriomotora e vasculite com acometimento difuso. ${ }^{12}$

É também descrito que a terapia com IFN- $\alpha$ desprovida de imunossupressores pode agravar a VC. ${ }^{11} \mathrm{O}$ emprego da prednisona oral, apesar da melhora cutânea, não promove benefícios no processo hepático que originou primariamente a doença. Por outro lado, a escolha de parâmetros, usados em diversos esquemas, como dose e medicações envolvidas, duração de tratamento, contraindicações e efeitos colaterais, transcende o objetivo do artigo.

\section{REFERÊNCIAS}

1. Hannon CW, Swerlick RA. Vasculitis. In: Bolognia JL, Jorizzo JL, Rapini RP, editors. Dermatology. London: Mosby; 2003. p. 381-402.

2. Hunder GG, Arend WP, Bloch DA, Calabrese LH, Fauci AS, Fries JF, et al. The American College of Rheumatology 1990 criteria for the classification of vasculitis. Introduction. Arthritis Rheum. 1990;33:1065-7.

3. Jennette JC, Falk RJ, Andrassy K, Bacon PA, Churg J, Gross WL, et al. Nomenclature of systemic vasculitides. Proposal of an international consensus conference. Arthritis Rheum. 1994;37:187-92.

4. Crissey JT, Parish LC. Vasculitis: the historical development concept. Clin Dermatol. 1999;17:493-7.

5. Fiorentino DF. Cutaneous vasculitis. J Am Acad Dermatol. 2003;48:311-40.

6. Hautmann G, Campanile G, Lotti TM. The many faces of cutaneous vasculitis. Clin Dermatol. 1999; 17:515-31.

7. Lotti T, Ghersetich I, Comacchi C, Jorizzo JL. Cutaneous small-vessel vasculitis. J Am Acad Dermatol. 1998; 39:667-87.

8. Jennette JC, Falk RJ. Small-vessel vasculitis. N Engl J Med. 1997;337:1512-23.

9. Blanco R, Martinez-Taboada VM, Rodrigues-Valverde V, Garcia-Fuentes M. Cutaneous vasculitis in children and adults: associated diseases and etiologic factors in 303 patients. Medicine. 1998; 77:403-18.

10. Brouet JC, Clauvel JP, Danon F, Lein M, Seligmann M. Biological and clinical significance of cryoglobulins: a report of 86 cases. Am J Med. 1974;57:775-88.
Umas das formas de avaliar o sucesso do tratamento da doença hepática é a verificação da resposta imunológica sustentada, observada por desaparecimento da carga viral ou redução de dois logs 12 semanas após o término do tratamento. ${ }^{13,14}$ Nesse caso, a paciente encontra-se em planejamento para introdução dessa terapêutica, após sua concordância.

\section{AGRADECIMENTOS}

Os autores agradecem ao Dr. Raphael Salles e à Dra. Mílvia M. S. S. Enokihara o suporte de diagnóstico histopatológico.
11. Stone JH, Nousari HC. "Essential" cutaneous vasculitis: what every rheumatologist should know about vasculitis of the skin. Curr Opin Rheumatol. 2001;13:23-34.

12. Ferri C, Mascia MT. Cryoglobulinemic vasculitis. Curr Opin Rheumatol. 2006;18:54-63.

13. Pascu M, Martus P, Hohne M, Wiedenmann B, Hopf U, Schreier E, et. al. Sustained virological response in hepatitis $\mathrm{C}$ virus type $1 \mathrm{~b}$ infected patients is predicted by the number of mutations within the NS5A-ISDR: a meta-analysis focused on geographical differences. Gut. 2004;53:1345-51.

14. Moreno-Otero R. Therapeutic modalities in hepatitis C: challenges and development. J Viral Hepat. 2005;12:10-9.

15. Manns MP, Obermayer-Straub P. Viral induction of autoimmunity: mechanisms and examples in hepatology. J Viral Hepat. 1997;(Suppl 2):S42-7.

ENDEREÇO PARA CORRESPONDENNCIA / MAILING ADDRESS:
Maurício Pedreira Paixão
Rua Teodoro de Beaurepaire, 208, ap. 151
O4279-030 São Paulo-SP
Tel./Fax: (11) 4493-5455
E-mail: mauriciopp@terra.com.br

ENDEREÇO PARA CORRESPONDÊNCIA / MAILING ADDRESS:

Rua Teodoro de Beaurepaire, 208, ap. 151

E-mail:mauriciopp@terra.com.br

Como citar este artigo / How to cite this article: Paixão MP, Miot HA. Vasculite cutânea crioglobulinêmica induzida por infecção crônica pelo vírus da hepatite C. An Bras Dermatol. 2008;83(2):151-5. 